\title{
Clean Diesel Component Improvement Program
}

Final Scientific/Technical Report

Reporting Period Start Date: $\quad$ August 31,2000

Reporting Period End Date: $\quad \underline{\text { June 30, } 2005}$

Project Director: $\quad$ Ralph Slone

DOE Award Number: DE-FC26-00OR22811

Recipient:

Noxtech, Inc.

1939 Deere Ave

Irvine, CA 92606

Teaming Member:

Analytical Engineering, Inc.

2555 Technology Blvd.

P.O. Box 2603

Columbus, IN 47202 


\section{DISCLAIMER}

"This report was prepared as an account of work sponsored by an agency of the United States Government. Neither the United States Government nor any agency thereof, nor any of their employees, makes any warranty, express or implied, or assumes any legal liability or responsibility for the accuracy, completeness, or usefulness of any information, apparatus, product, or process disclosed, or represents that its use would not infringe privately owned rights. Reference herein to any specific commercial product, process, or service by trade name, trademark, manufacturer, or otherwise does not necessarily constitute or imply its endorsement, recommendation, or favoring by the United States Government or any agency thereof. The views and opinions of authors expressed herein do not necessarily state or reflect those of the United States Government or any agency thereof." 


\section{Executive Summary}

The research conducted in this program significantly increased the knowledge and understanding in the fields of plasma physics and chemistry in diesel exhaust, the performance and characteristics of multifunctional catalysts in diesel exhaust, and the complexities of controlling a combination of such systems to remove NOx.

Initially this program was designed to use an in-line plasma system (know as a plasma assisted catalyst system or PAC) to convert NO $\rightarrow$ NO2, a more catalytically active form of nitrogen oxides, and to crack hydrocarbons (diesel fuel in particular) into active species. The $\mathrm{NO}_{2}$ and the cracked hydrocarbons were then flowed over an in-line ceramic NOx catalyst that removed $\mathrm{NO}_{2}$ from the diesel exhaust. Even though the PAC system performed well technically and was able to remove over $95 \%$ of NOx from diesel exhaust the plasma component proved not to be practical or commercially feasible. The lack of practical and commercial viability was due to high unit costs and lack of robustness.

The plasma system and its function was replaced in the NOx removal process by a cracking reforming catalyst that converted diesel fuel to a highly active reductant for NOx over a downstream ceramic NOx catalyst. This system was designated the ceramic catalyst system (CCS). It was also determined that NO conversion to $\mathrm{NO}_{2}$ was not required to achieve high levels of $\mathrm{NOx}$ reduction over ceramic NOx catalyst if that catalyst was properly formulated and the cracking reforming produced a reductant optimized for that NOx catalyst formulation. This system has demonstrated $92 \%$ NOx reduction in a diesel exhaust slipstream and $65 \%$ NOx reduction from the full exhaust of a $165 \mathrm{hp}$ diesel engine using the FTP cycle. Although this system needs additional development to be commercial, it is simple, cost effective (does not use precious metals), sulfur tolerant, operates at high space velocities, does not requirea second fluid be supplied as a reductant, has low parasitic loss of $2-3 \%$ and achieves high levels of NOx reduction.

This project benefits the public by providing a simple low-cost technology to remove NOx pollutants from the exhaust of almost any combustion source. The reduction of NOx emissions emitted into the troposphere provides well documented improvement in health for the majority of United States citizens. The emissions reduction produced by this technology helps remove the environmental constraints to economic growth.

Program Goals:

The initial program goals of this project were:

- Design, build, and improve a PAC system capable of treating the exhaust of an 80 -hp diesel engine. Use that system to demonstrate $90 \%$ NOx reduction 
- Design, build and improve a PAC system capable of treating the exhaust of a 200 -hp engine. Use that system to demonstrate $90 \%$ NOx reduction.

- Design, build and improve a PAC system capable of treating the exhaust of a 400-hp diesel engine. Use that system to demonstrate $90 \%$ NOx reduction.

Since only $60 \%$ of the funding originally designated for the project was received by Noxtech, the project goals were revised to:

- Design, build, and improve a PAC system capable of treating the exhaust of an 80 -hp diesel engine. Use that system to demonstrate $90 \%$ NOx reduction

- Design, build and improve a PAC system capable of treating the exhaust of a 200 -hp engine. Use that system to demonstrate $90 \%$ NOx reduction.

Accomplishments/objects achieved by the Program:

- A PAC system demonstrated $95 \%$ NOx reduction on the exhaust of an $80-$ hp engine.

- The ceramic catalyst system (CCS) demonstrated $65 \%$ NOx reduction on a 165-hp diesel engine exhaust.

- The CCS demonstrated $92 \%$ NOx reduction on a slipstream from a diesel engine.

\section{Discussion}

\section{Plasma Assisted Catalyst System}

The original basis for $\mathrm{NOx}$ reduction using a PAC system was to react $\mathrm{NO}_{2}$ with cracked hydrocarbons, both created with an in-line plasma reactor, over a NOx reduction catalyst and convert it to $\mathrm{N}_{2}+\mathrm{H}_{2} \mathrm{O}$ and $\mathrm{CO}_{2}$. More specifically, diesel fuel or another suitable hydrocarbon was injected into a non-thermal plasma generated in-line in the exhaust stream. The plasma generated a high energy stream of electrons that cracked the injected hydrocarbon a portion of which then reacted with $\mathrm{O} 2$ to form $\mathrm{O} 3$ that reacted with $\mathrm{NO}$ to form $\mathrm{NO}_{2}$. The remainder of the cracked hydrocarbons flowed downstream in the exhaust and reacted with an in-line NOx reduction catalyst (Figure 1.) 
Figure 1.

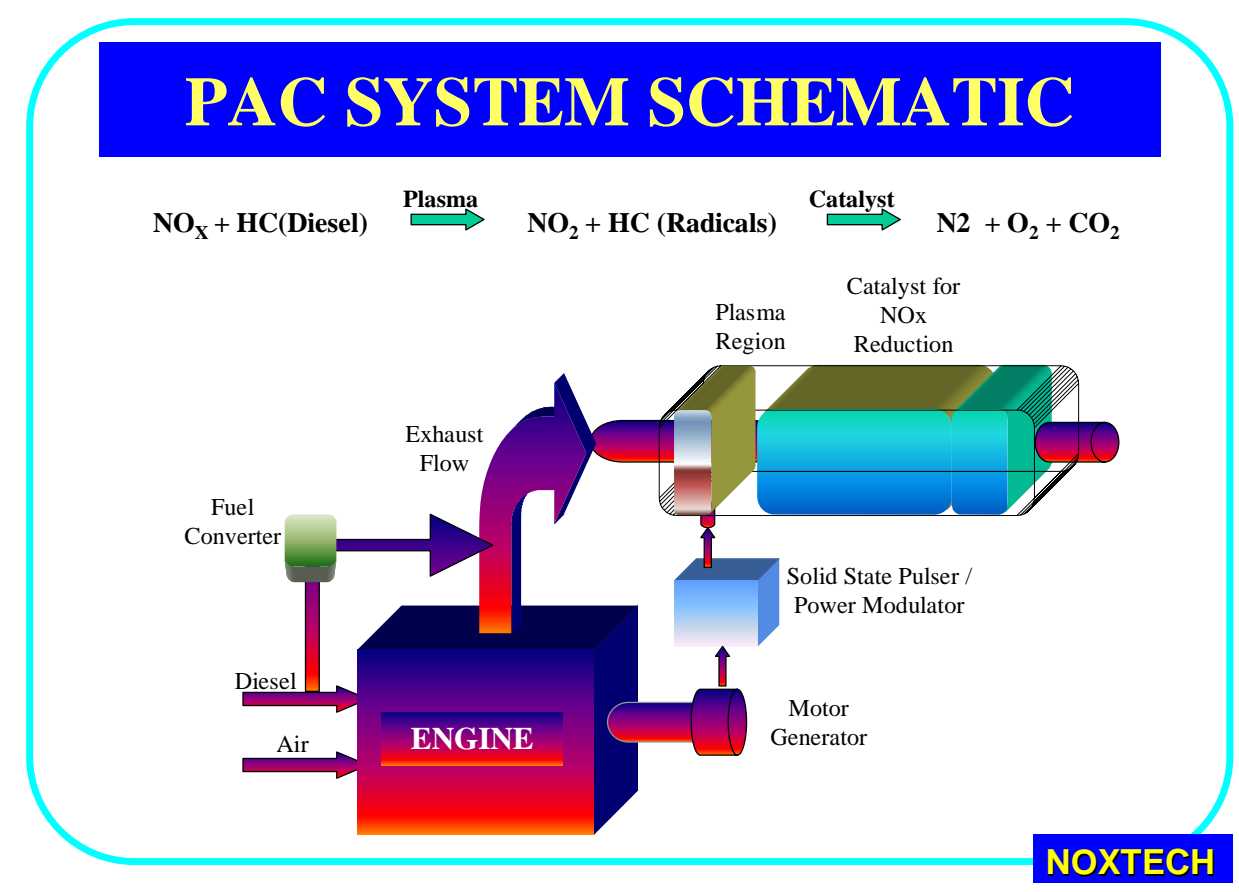

Non-thermal plasma is created by short (nanosecond time scale) high voltage pulses $(10-30 \mathrm{kV})$. Highly energetic electrons generated by the intense electric field produce reactive free radicals, which on reaction with NO, produce oxidized Ncontaining intermediates. These intermediates are then reduced to $\mathrm{N}_{2}$ on the surface of a selective catalyst, placed downstream from the plasma. The plasma efficiency and the activity on the subsequent catalyst are facilitated by the presence of hydrocarbon $(\mathrm{HC})$. In the plasma environment, the $\mathrm{HC}$ leads to a propensity of $\mathrm{HOi}^{*}$ radicals, which primarily oxidizes $\mathrm{NO}$ to $\mathrm{NO}_{2}$. On the surface of the downstream catalyst, the $\mathrm{HC}$ initiates a series of intermediate steps, the overall effect of which is the oxidation of the $\mathrm{HC}$ and the simultaneous reduction of NOx to $\mathrm{N}_{2}$. This system defines the plasma-assisted catalytic (PAC) reactor.

In this scheme the plasma reactor and high voltage power supply are the most complicated parts of the total PAC reactor. The design of the plasma reactor and high voltage pulser determines the integrity of this system to provide efficient energy transfer from the pulser to the plasma reactor. The total efficiency comprises the efficiency of DC-to-pulser conversion, the efficiency of energy transfer to plasma, and the efficiency of energy deposition in plasma. The targeted total energy consumption was $<5 \%$ of engine power.

Two different plasma reactor designs were developed and demonstrated. They were the multi-coax tube reactor and the sandwich reactor. The coax tube reactor consisted of a series of cylindrical corona discharge reactors mounted in parallel (Figure 2.) The sandwich reactor was a stacked electrode plasma generator (Figure 3.) Both of these reactors functioned well on a laboratory basis but were not commercially capable. These designs were not practical to be 
manufactured in large quantities nor were they robust enough to stand the stresses they would experience when installed on a truck. The performance of these systems is shown in Figure 4.

Figure 2.

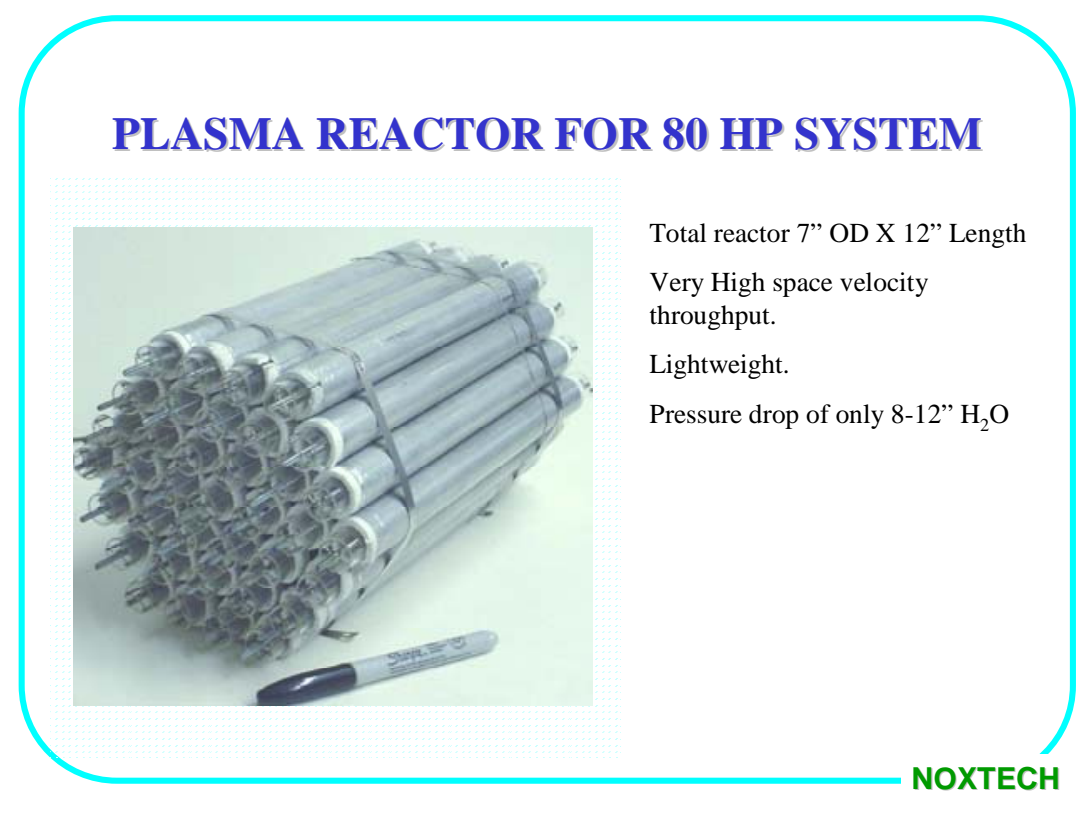

Figure 3. (View of Plasma in Operation)

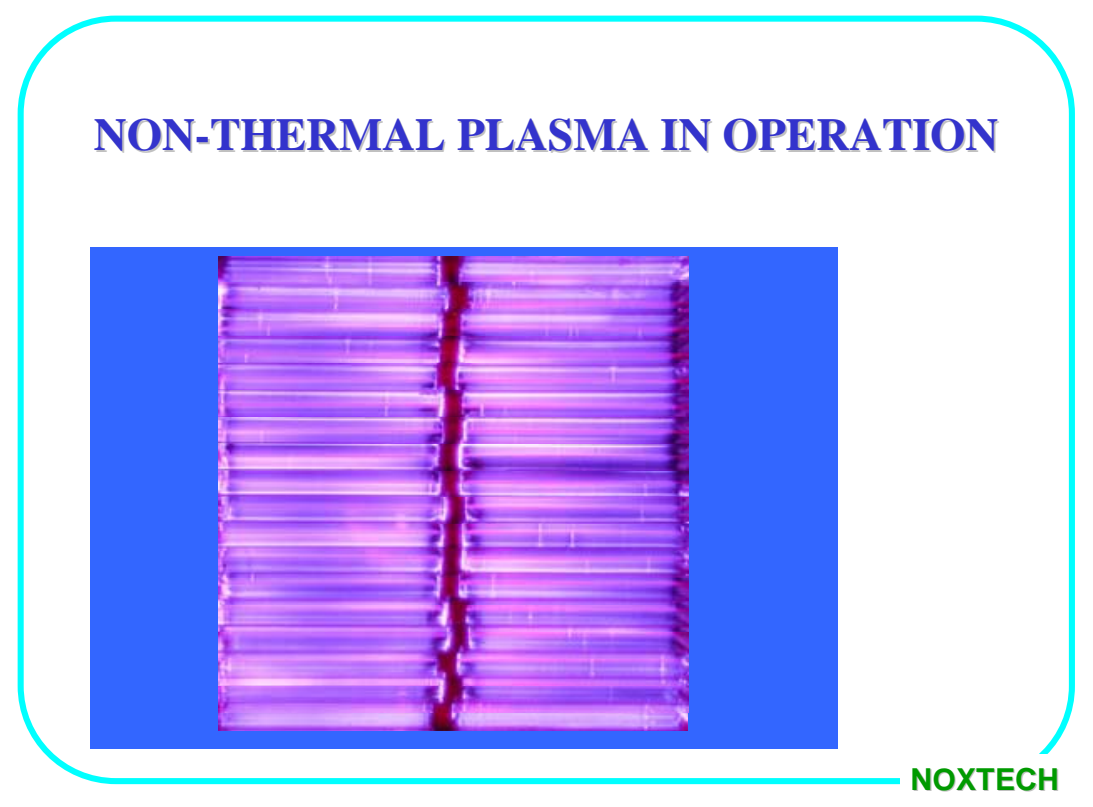

For a cost-effective and reliable PAC system, a solid-state pulser was critical as it eliminates periodic maintenance and increases efficiency and power supply life cycle. The solid state pulser amplified the voltage from commercially available 
power sources such as a $110 \mathrm{~V}$ from the grid or a 24 volt from a vehicle to 10,000 volts. The solid-state pulser also had to switch this high voltage in 50 nanoseconds or less to create an optimum plasma. The high voltage switching required an extremely robust single crystal power transistor. A further advantage of the solidstate pulser developed and built by Noxtech was its versatility. This pulser allows adjusting pulse parameters to some extent in accordance with the plasma reactor. The total electrical efficiency of this pulser is about $80 \%$ and needed further improvement. A significant effort was directed towards increasing its efficiency to $95 \%$ but did not produce a workable system. This work was focused on improving the ferrite cores that are key to the performance of the inductive adder SS pulser. Although, the developed solid-state pulser worked well on a pilot basis it needed an additional major effort and funding to produce a commercially capable system.

The ceramic NOx reduction catalyst was also a critical component for the Noxtech PAC system. It had to be properly matched with the cracked hydrocarbons, produced by the plasma reactor, to optimize the reduction of $\mathrm{NO}_{2}$ on its surface. This catalyst had to also minimize or eliminate the formation of carbon and/or polymer surface deposits from the hydrocarbon reductant formed by the plasma reactor. Noxtech was never able to demonstrate an acceptable rate of deposit formation on these catalysts although over 30 catalysts were screened for this program.

Although Noxtech was able to demonstrate over 95\% NOx reduction (Figure 4.) on a pilot scale in diesel exhaust using the PAC system, it was neither cost effective nor robust enough for commercial use. These tests were conducted over a temperature range of 200 degreees $C-500$ degrees $C$, a space velocity of $30,000 \mathrm{hr}-1$, and at a parasitic fuel useage of $2.5 \%$. It would have required more time, effort and funding than was available from Noxtech and/or DOE. The primary challenge was the development of a commercially capable plasma system. It was decided in 2004 to modify the process to make it more viable to develop and demonstrate a more practical commercially capable system using the available funding.

Figure 4.

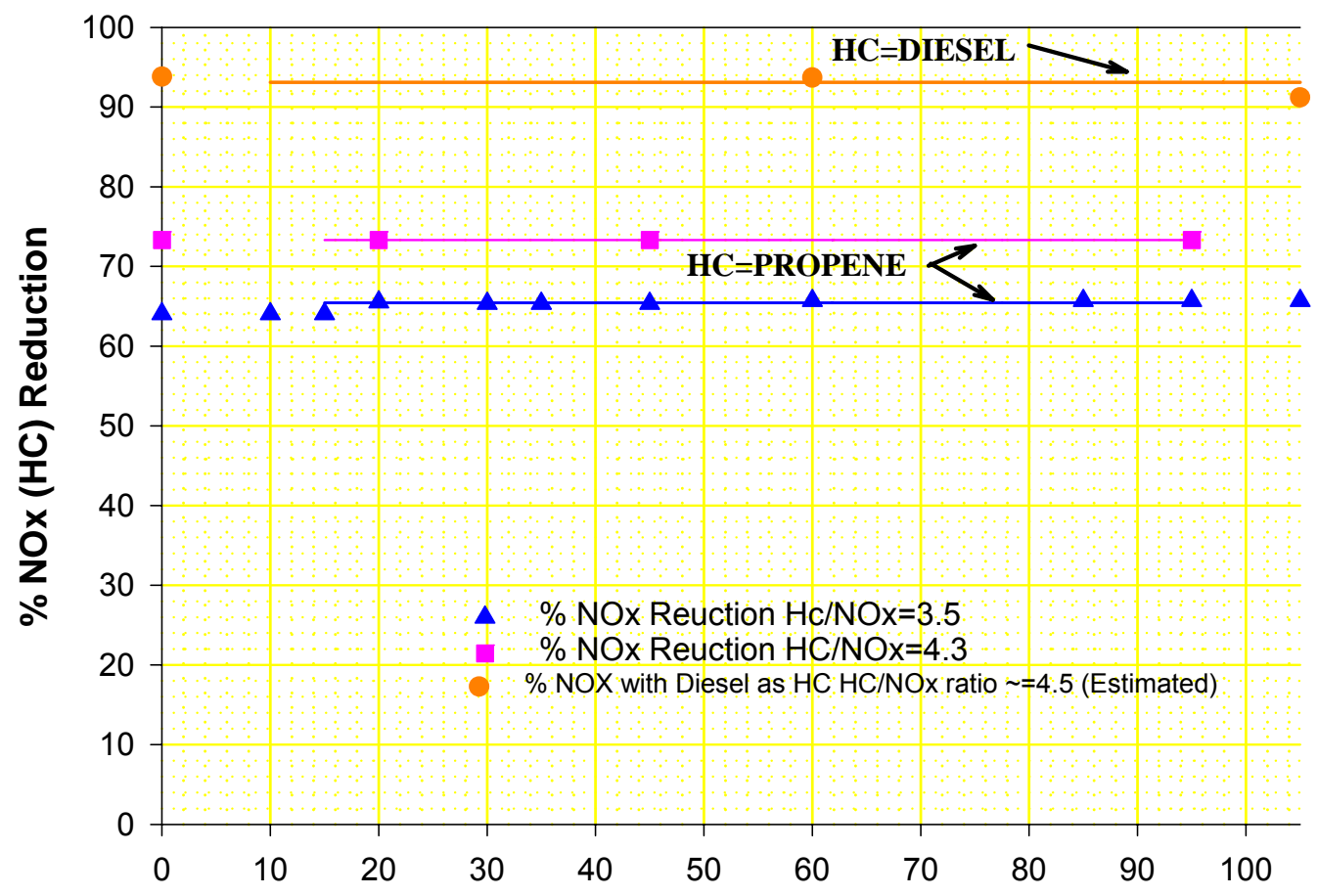




\section{Ceramic Catalyst System}

Originally it was thought that a plasma reactor was needed to convert $\mathrm{NO}$ to $\mathrm{NO}_{2}$ and to crack diesel fuel to produce a reductant before flowing this mixture over a $\mathrm{NOx}$ reduction catalyst. The work in this project found that both $\mathrm{NO}$ and $\mathrm{NO}_{2}$ could be reacted simultaneously with a reductant formed from a cracking/reforming catalyst and a compatible ceramic NOx reduction catalyst. This eliminated the need for a plasma reactor in the NOx reduction system and greatly simplified and reduced the cost of this system. Thus, with the approval of DOE, the project shifted to the development of a Ceramic Catalyst System (CCS).

The CCS consists of a small cracking/reforming catalyst reactor (Figure 5.), external from the exhaust stream, that will crack and reform a hydrocarbon (preferable diesel fuel or gasoline) to form a very active reductant consisting of cracked and partially oxidized hydrocarbon species. These reductants are optimized for NOx reduction (short chain HC fractions) over a Ceramic NOx reduction catalyst by controlling the catalyst(s) composition and operating conditions: temperature, $\mathrm{hr}-1$ and oxygen concentration. The reductants formed in the cracking/reforming reactor are injected into the exhaust upstream of a ceramic NOx reduction catalyst. No precious metals are used in the cracking/reforming catalyst.

A doped ceramic $\mathrm{NOx}$ reduction catalyst $\left(\mathrm{Mo} / \mathrm{Cu}\right.$ doped $\left.\mathrm{SiO}_{2}\right)$ is placed in-line with the exhaust flow and down stream from the injection of reductants formed by the cracking/reforming catalyst. NOx in the exhaust combines with the active reductants on the surface of the ceramic $\mathrm{NOx}$ reduction catalysts to form $\mathrm{CO}_{2}$, $\mathrm{H}_{2} \mathrm{O}$ and $\mathrm{N}_{2}$. The ceramic NOx reduction catalyst contains no precious metals and is not susceptible to sulfur poisoning or deactivation. The CCS system has several features that make it a very commercially attractive system for reducing NOx from combustion sources and in particular diesel engines:

Dow Cost: System does not use precious metals and is relatively simple to control, design and build.

$>$ Single fluid: System uses a readily available fluid (diesel or gasoline) that is catalytically reformed to produce a reductant that eliminates ammonia slip characteristic of nitrogen reductant based systems

$>$ Low parasitics (operating costs): System requires $2-2.5 \%$ of power system's rated fuel consumption.

$>$ Practical size: This system will be able to replace the muffler on transportation vehicles.

Dimplicity: CCS is expected to be relatively simple to install and operate. 
$>$ Highly durable components with no sensitivity to sulfur poisoning and thermal cycle degradation.

Figure 5.
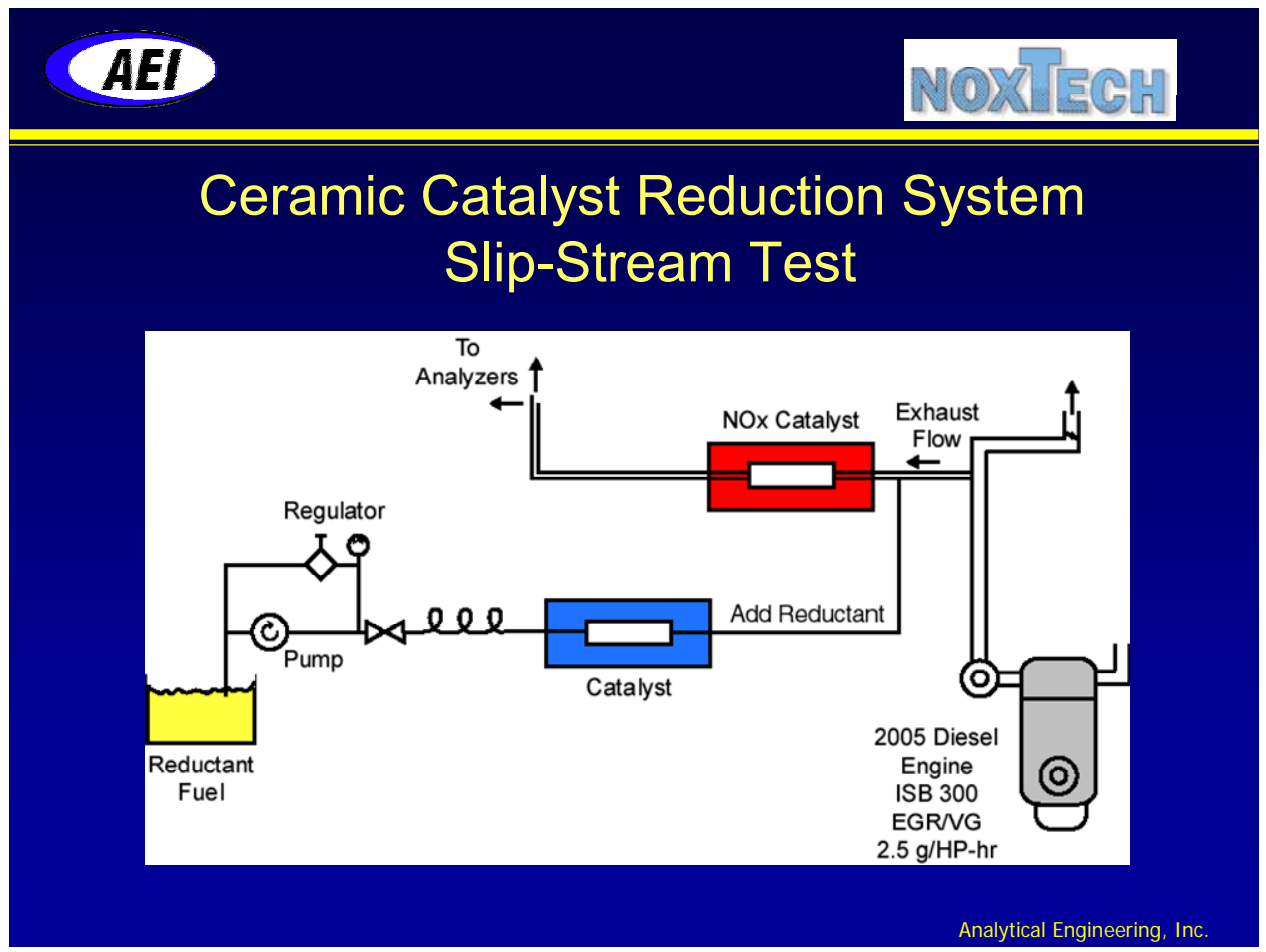

The work on the CCS for this program focused on the development and enhancement of the catalysts used in the CCS. Work was conducted with several major catalyst companies that took advantage of their special capabilities. The catalyst development work is described in the subsequent text.

Viable generation of a reactive reductant from diesel fuel is a critical requirement for this project. The development work conducted during this project in conjunction with several major commercial catalyst companies demonstrated that tailored reductants could be generated by properly and uniquely formulated cracking/reforming catalysts. Functional reductants (that vary with the catalyst combination) were generated from non-precious metal catalysts that are sulfurtolerant and thermally stable. It was demonstrated that these reductants reacted efficiently and effectively on the surface of a ceramic NOx catalyst without producing undesirable by-products (solid or gaseous). The reductant formation process was refined and controlled to produce the optimum species (that vary with the catalyst combination) for reaction with NOx from on the NOx catalyst surface but also to prevent the formation of solids on the catalyst surface and/or noxious gaseous species. 
The effective NOx reduction operating temperature range goal for the CCS to demonstrate over $90 \%$ NOx reduction was 150-600 Co. Experimental ceramic materials $\left(\mathrm{Mo} / \mathrm{Cu}\right.$ doped $\left.\mathrm{SiO}_{2}\right)$ from three major catalyst companies were evaluated because they offer higher surface areas/unit mass, the ability to control selectivity of species through cage size/cage surface properties (substituting doping metals into the cage structure) and by optimizing the basic crystal structure to make these materials more active at lower temperatures. High surface area doped ceramic catalysts of a different composition from those described above are also being designed and evaluated to enhance low temperature activity and selectivity for NOx reduction. It should be noted that achieving the activity goals over the designated operating temperature range for this program required the optimization and matching of the reductant species and the species to be reduced (NO/NO2) in addition to the catalysts.

The ultimate goal of this program was to demonstrate on a full scale basis $94 \%$ NOx reduction from the exhaust of a diesel engine at $50,000 \mathrm{hr}^{-1}$. This required a reduction of catalyst volume by Increasing operating hr- ${ }^{1}$ to 50,000 from 30,000 . Catalyst effectiveness or efficiency/unit mass of catalyst was improved through increasing normalized surface areas and making the catalyst more selective. This program is enhancing surface area by customizing ceramic catalysts to maximize surface areas (over $900 \mathrm{M}^{2} / \mathrm{gm}$ ) and by optimizing pore sizes/and surface binding capabilities through doping of the basic ceramic crystals.

Catalyst durability also needs to be enhanced. NOx catalyst durability is determined by its thermal and chemical stability when exposed to the exhaust of a diesel engine. The durability of the CCS catalysts has been enhanced and assured by selecting and optimizing modified ceramic based materials, that are inherently very thermally stable but also have a minimum of metals (no precious metals) that are available to react with poisons, sulfur in particular, in the exhaust to form stable inactive compounds with the catalyst or produces $\mathrm{SO}_{\mathrm{x}}$ compounds that are undesirable. The doping metals in the ceramic catalysts being used in the PAC are not available to react with the sulfur compounds in the diesel exhaust nor to react thermally to grow into larger crystallites reducing the active surface of these catalysts.

Although constrained by time and resources, the results of the development work already performed clearly demonstrate the technical viability of this technology.

- Demonstrated 92\% NOx reduction on an exhaust slip stream from a Cummins ISB 9.5L diesel engine producing $2.5 \mathrm{~g} / \mathrm{bhp}$-hr of NOx at $200,000 \mathrm{hr}-1,2 \%$ parasitic loss and with $500 \mathrm{ppm}$ SOx (commercial diesel fuel) in the exhaust stream (Figure6). Slip stream flow was $19 \mathrm{scfm}$ and was $5 \%$ of the total exhaust flow from the engine and the volume of the NOx catalyst was $8.41 \mathrm{in}^{3}$. The results from this test were very repeatable. 
- Demonstrated 65\% NOx reduction over the FTP transient cycle on the full exhaust flow from $165 \mathrm{hp}$ diesel engine with 500 ppm Sox (Figure 7.)

- Formulated over 20 unique cracking/reforming and NOx reduction catalysts

- Low Cost: System does not use precious metals and is relatively simple to control, design and build.

- Single fluid: System uses a readily available fluid (diesel or gasoline) that is catalytically reformed to produce a reductant that eliminates ammonia slip characteristic of nitrogen reductant based systems

- Low parasitics (operating costs): System requires $2-2.5 \%$ of power system's rated fuel consumption.

- Practical size: This system will be able to replace the muffler on transportation vehicles.

- Simplicity: CCS is expected to be relatively simple to install and operate.

- Highly durable components with no sensitivity to sulfur poisoning and thermal cycle degradation.

A significant effort is still required to refine and optimize the catalysts used in this system to demonstrate commercial viability of the CCS to meet current and future NOx emissions regulations for over-the-road diesel trucks and exhausts from other hydrocarbon combustion sources. Analytical Engineering, Inc. and Noxtech are continuing to develop this technology using in-house resources.

The ceramic catalyst system is desperately needed to meet current and future NOx reduction legislation since the most prominent approaches presently being developed present many problems and difficulties. Catalyst poisoning, high costs, thermal cycling, parasitic losses and supplying a practical reductant make the performance and life of NOx adsorbers and lean NOx catalysts problematic. SCR's require an external fluid to be commercially distributed and carried on commercial vehicles. This presents significant enforcement issues. Combustion control technologies such as EGR, high injection pressures, variable geometry turbine for air handing and other similar mechanisms used to control NOx emissions from diesel engines add complexity, cost and reduce reliability and efficiency. 
Figure 6.

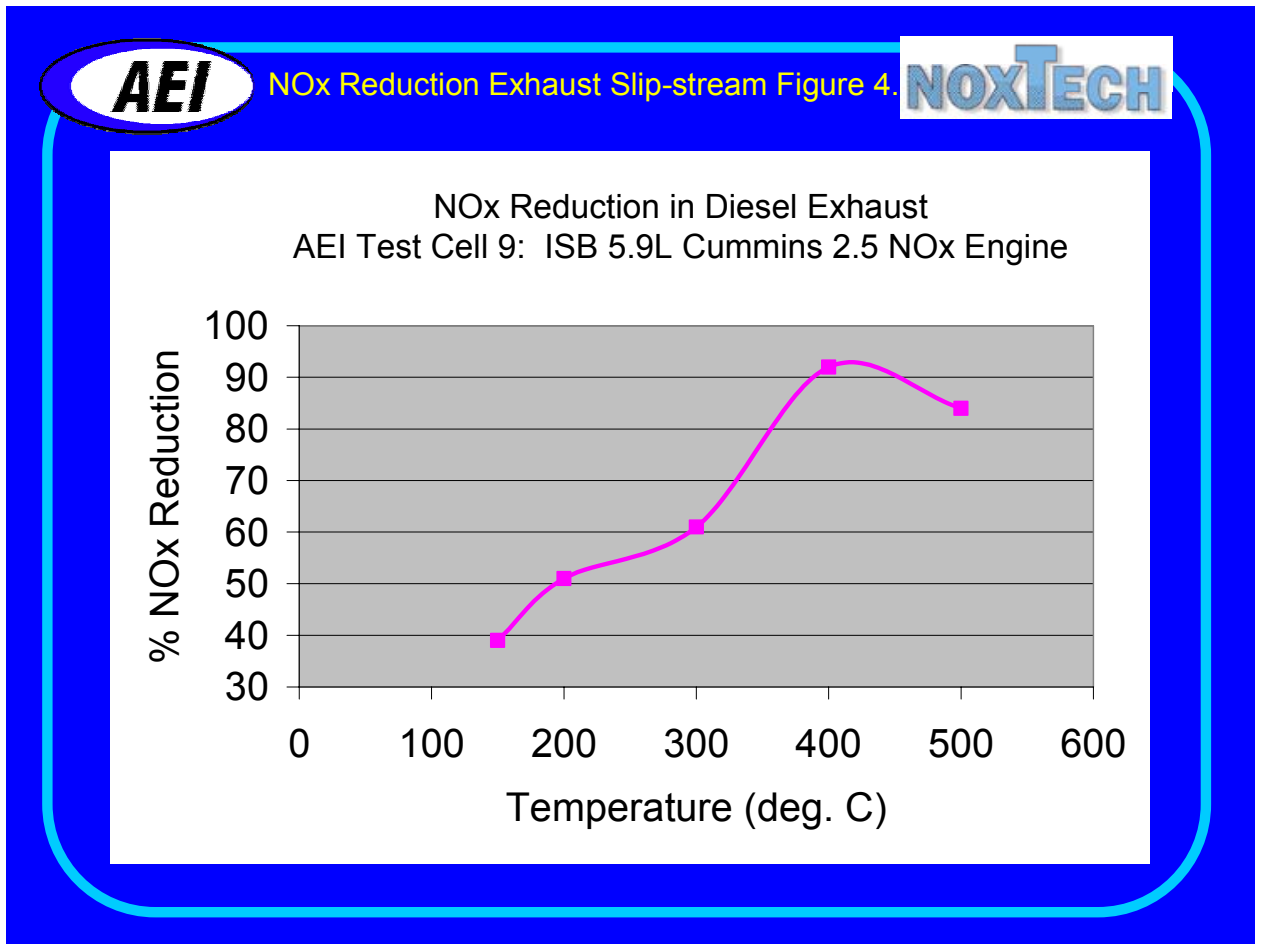

Figure 7.

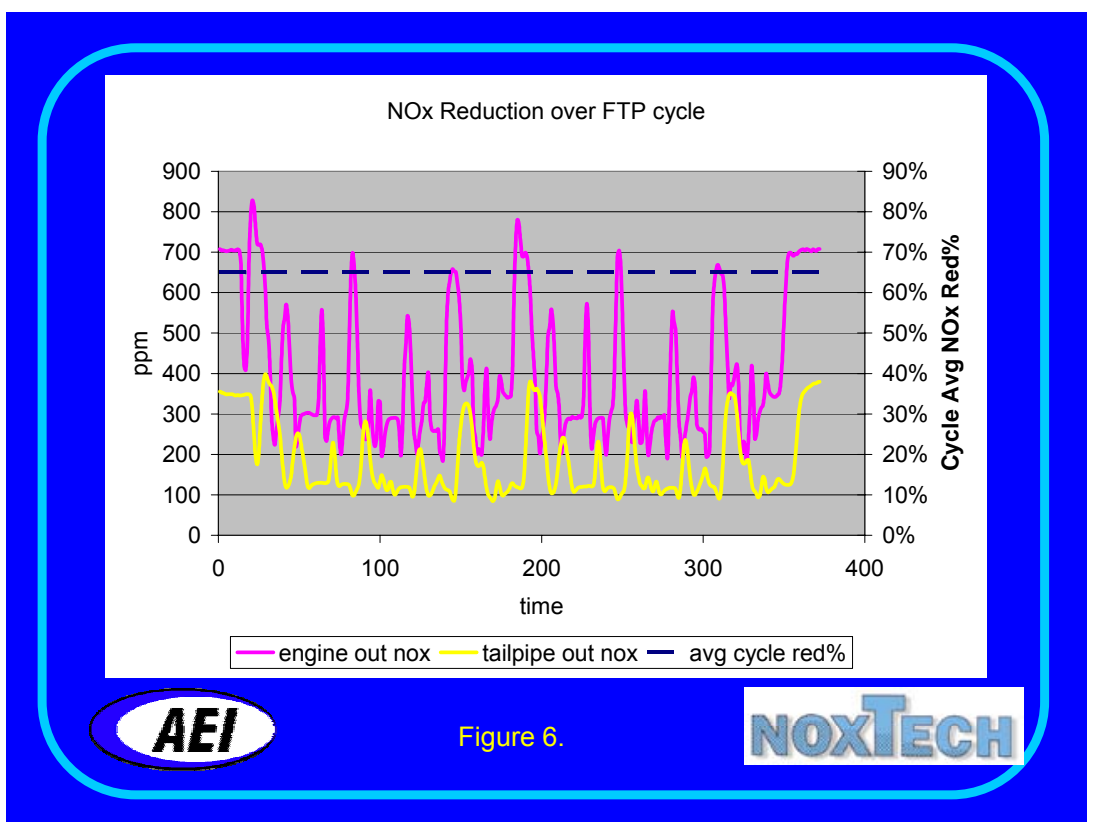


Products developed under the award and technology transfer activities:

- Publications:

1. "Nox Reduction for Lean Exhaust Using Plasma Assisted Catalysis", Ralph Slone, Barry Bhatt and Victor Puchkarev of Irvine, CA; presented at the 2001 DOE Diesel Engine Emissions Reduction (DEER) Conference

2. "Clean Diesel Engine Improvement Program Plasma Assisted Catalyst for NOx and Particulate Removal", Ralph Slone, Barry Bhatt and Victor Puchkarev of Irvine, CA; presented at the 2002 DOE Diesel Engine Emissions Reduction (DEER) Conference

3. "Noxtech's Plasma-Assisted Catalyst System Development and Demonstration", Ralph Slone, Irvine, CA presented at the 2003 DOE Diesel Engine Emissions Reduction (DEER) Conference

4. "Plasma Assisted Catalyst System for NOx Reduction", Ralph Slone, Irvine, CA presented at the 2004 DOE Diesel Engine Emissions Reduction (DEER) Conference

5. "NOx Reduction In Diesel Exhaust Using Ceramic Catalysts", Ralph Slone, Irvine, CA presented at the 2005 DOE Diesel Engine Emissions Reduction (DEER) Conference

- Networks or collaborations fostered:

1. Development and collaboration with several major catalyst companies

2. Development and collaboration with companies that design, develop and supply high energy physics components

3. Engine design/testing and emissions control development and testing: Analytical Engineering, Inc.

- Inventions/Patents:

1. United States Patent No. $6,475,350$, "Method for Removing NOx and Other Pollutants From Gas Streams Using a Plasma Assisted Catalyst", By Vishwesh Palekar and Ralph Slone.

2. Application in Process U. S. Patent Office: "NOx Reduction System and Method". 